\title{
UPACARA TARAPAN DALAM BUDAYA JAWA (SUATU KAJIAN PENDIDIKAN DALAM UPAYA PELESTARIAN KEARIFAN LOKAL)
}

\author{
Sri Iswanti \\ FIP UniversitasNegeri Yogyakarta \\ email: sri_iswansti@uny.ac.id
}

\begin{abstract}
Abstrak: Upacara Tarapan dalam Budaya Jawa (Suatu Kajian Pendidikan dalam Upaya Pelestarian Kearifan Lokal). Penelitian ini bertujuan mendeskripsikan konsep upacara tarapan, tata cara pelaksanaan upacara tarapan, dan nilai pendidikan yang terdapat dalam upacara tarapan dalam budaya Jawa. Lokasi penelitian di Daerah Istimewa Yogyakarta sebagai pusat budaya Jawa. Subjek penelitian adalah mereka yang memahami berbagai upacara tradisional Jawa, sesepuh serta para pemerhati budaya dan tradisi Jawa. Pengumpulan data dilakukan dengan dokumentasi dan wawancara. Uji keabsahan data dengan perpanjangan waktu penelitian, triangulasi, dan pemeriksaan data deskriptif kepada informan yang kompeten. Teknik analisis data meliputi tiga kegiatan utama, yakni reduksi data, penyajian data, dan penarikan kesimpulan atau verifikasi. Hasil penelitian sebagai berikut. Pertama, upacara tarapan merupakan upacara inisiasi bagi anak perempuan yang mendapatkan haid pertama. Kedua, pelaksanaan upacara tarapan dilakukan sesuai dengan empat kelompok sosial, yaitu: (1) golongan bangsawan, (2) golongan rakyat biasa, (3) golongan petani di pedesaan tepi pantai, dan (4) golongan masyarakat beragama Buddha. Ketiga, di dalam upacara tarapan terkandung butir-butir kearifan lokal yang bermuatan nilai pendidikan yang berguna bagi remaja dan orang tua.
\end{abstract}

Kata kunci : upacara tradisional, budaya Jawa, nilai pendidikan, dan kearifan lokal

\begin{abstract}
Tarapan Ceremony In Java Culture (An Educational Study of The Local Wisdom Preservation Efforts). This study is aimed to describe the concept of tarapan ceremony, the ceremony tarapan procedures, and educational value contained in tarapan ceremony in Javanese culture. The research location is in Yogyakarta Special Region as the center of Javanese culture. The research subjects were those who understand the traditional Javanese ceremonies, elders and students of Javanese culture and tradition. The data was collected through interviews and documentation. The data validity was tested using extra-time research, triangulation, and examination of descriptive data to the competent informants. Data analysis techniques include the three main activities, namely data reduction, data display and conclusion drawing or verification. The results are these following. First, the tarapan ceremony is an initiation ceremony for girls for their first period. Second, the implementation of tarapan ceremony conducted in accordance with the four social groups, namely : ( 1 ) the nobility, ( 2 ) groups of ordinary people, ( 3 ) categories of farmers in rural areas by the beach, and ( 4 ) groups of Buddhists people. Third, in the tarapan ceremony is contained grain indigenous value-laden education that is useful for adolescents and parents.
\end{abstract}

Keywords : traditional ceremony, Javanese culture, education values, and local wisdom

\section{PENDAHULUAN}

Kearifan lokal khususnya yang bersumber dari budaya Jawa merupakan hasil pemikiran yang didahului oleh pengamatan, perenungan, pengendapan, dan uji coba masyarakat terdahulu yang tercermin dalam 
dokumen naskah dan tradisi masyarakat. Perubahan budaya terjadi terus menerus seiring berjalannya waktu, yang menyebabkan budaya orang tua sangat jauh berbeda dengan budaya atau gaya hidup anak muda, sehingga timbul kesenjangan yang semakin lebar antara nilai-nilai kearifan budaya dengan orientasi kehidupan generasi muda sekarang. Kearifan lokal yang sering disebut sebagai budaya "lama”, "kuno", atau "ketinggalan" semakin terasing dalam masyarakat sendiri dan semakin tidak dikenal bahkan tidak "communicable" di kalangan generasi muda, yang akhirnya kearifan yang berasal dari budaya lokal hanyalah menjadi bagian masa lalu. Istilah "tarapan" tidak dikenal lagi oleh masyarakat umum lebih-lebih oleh generasi muda

Melihat kondisi dan latar belakang Daerah Istimewa Yogyakarta yang kaya akan budaya Jawa bahkan disebut sebagai sumber budaya Jawa tersebut sangat dirasakan perlunya menggali dan memahami makna "tarapan" sebagai kearifan lokal baik dari dokumen maupun dari para lanjut usia sebagai data primer dan menemukan nilai-nilai pendidikan yang terkandung dalam upacara tarapan tersebut. Untuk itu diperlukan penelitian untuk mendeskripsikan pelaksanaan upacara tarapan dalam budaya Jawa, dan menemukan butir-butir kearifan lokal yang bermuatan nilai pendidikan dalam upacara tarapan

Upacara tradisional memiliki arti penting bagi kehidupan bersama dalam masyarakat. Van Gannep (Koentjaraningrat, 1985 : 32) menyatakan bahwa pelaksanaan upacara tradisional dapat untuk menimbulkan kembali semangat kehidupan sosial antara warga masyarakat. Upacara tarapan merupakan salah satu dari daur kehidupan manusia, yaitu daur kehidupan menuju masa dewasa. Hal ini sesuai yang dikemukakan oleh Departemen Pendidikan dan Kebudayaan (1982) yang membagi daur kehidupan manusia menjadi empat tahapan besar, yaitu : masa kehamilan, masa kelahiran dan masa bayi, masa kanak-kanak, dan masa dewasa. Upacara masa dewasa dilaksanakan apabila anak-anak, baik laki-laki maupun perempuan memasuki masa dewasa dan mengakhiri masa kanak-kanak.

Upacara tarapan merupakan upacara yang diperuntukkan bagi anak perempuan yang mendapatkan haid pertama kali, biasanya pada usia sekitar 12 sampai 15 tahun. Secara umum upacara tarapan dimaksudkan untuk: 1) menghindarkan individu yang dalam keadaan kritis dari gangguan gaib. 2) menyatakan kepada khalayak ramai bahwa individu yang diupacarai telah memasuki status sosial yang baru, yaitu dari masa kanak-kanak menuju masa remaja/dewasa. Semenjak saat itu, anak perempuan tersebut sudah siap (secara fisik) untuk dibuahi dan menjalani kehamilan sebagai salah satu tugas seorang perempuan. 3) memberikan pendidikan kepada individu yang bersangkutan bahwa dia sudah memasuki tahap kehidupan yang lebih tinggi yaitu kehidupan masa dewasa. Dari beberapa tujuan tersebut dapat diduga, bahwa dalam upacara tarapan tersebut terkandung butir-butir kearifan lokal yang bermuatan nilai-nilai pendidikan bagi anak remaja maupun bagi orang tuanya.

Pelaksanaan upacara dilakukan selama tujuh hari setelah permulaan haid yang pertama, sehingga upacara ini tidak dapat direncanakan dengan pasti. Pada jaman dahulu, seorang gadis tersebut tidak diijinkan keluar rumah yang disebut dengan istilah "dipingit". Selama tujuh hari dilakukan pengasingan dalam kamar tersendiri. Pada saat pengasingan ini secara silih berganti, ibu, sanak saudara perempuan, dan para pinisepuh melakukan tuguran (tidak tidur di malam hari) secara bergiliran. Maksudnya untuk menemani saat pengasingan, juga untuk memberikan nasehat dan bekal hidup bagi anak tarap mengenai tugas, kewajiban, pantangan, anjuran, yang harus dilakukan sesudah memasuki masa dewasa. Selesai hari ketujuh, akan dilanjutkan dengan siraman, dikenakan pakaian adat lengkap, kemudian diberi berbagai obat-obatan tradisional yang berupa jamu mamahan dan jamu godhogan, menelan telur mentah, diberi 
alas duduk yang berasal dari dedaunan dan empon-empon, yang semuanya dimaksudkan untuk menjaga kesehatan, kebugaran, serta kecantikan dari anak tarap. Pemberian jamu-jamu tradisional tersebut, juga merupakan pendidikan perilaku hidup yang sehat yang harus dilakukan oleh seorang perempuan. Selanjutkan akan dilaksanakan kenduri dan pembacaan doa untuk memohon keselamatan.

Dari langkah-langkah pelaksanaan upacara tarapan tersebut, dapat dilihat bahwa berbagai topik tentang pendidikan seksual dapat diberikan melalui upacara tarapan. Mulai dari kondisi fisik seorang perempuann yang sudah mengalami haid, tugas dan kewajiban, pantangan dan anjuran, sampai cara-cara menjaga kesehatan, kebugaran, dan kecantikan perempuan.

\section{METODE}

Penelitian ini menggunakan pendekatan kualitatif untuk mengkaji secara mendalam tentang upacara tarapan. Pendekatan ini berusaha mengungkapkan gejala secara menyeluruh sesuai dengan konteks (holistik-kontekstual) melalui pengumpulan data dari latar alami. Pendekatan kualitatif yang digunakan adalah deskriptif kualitatif, yaitu suatu penelitian yang bertujuan untuk mendeskripsikan gejala yang menjadi fokus penelitian. Data kualitatif yang dikumpulkan merupakan data deskriptif berupa kata-kata, tindakan dan dokumen dari nara sumber atau subjek penelitian. Makna penelitian diangkat dari konteksnya, dari sudut pandang subjek. Pemanfaatan teori-teori yang relevan sebagai pisau analisis data kualitatif dapat menghasilkan deskripsi yang bermakna.

Subjek penelitiannya adalah mereka yang memahami berbagai upacara tradisional Jawa, pelaku budaya Jawa, serta pemerhati budaya dan tradisi Jawa, yang terdiri dari : (1) perempuan yang ketika gadis/saat memperoleh haid yang pertama menjalani upacara tarapan (yang kini usianya sudah tidak muda lagi); (2) para orang tua yang pernah melaksanakan upacara tarapan bagi anak gadisnya, (3) Pakar dan pengamat bu- daya Jawa yang memahami tentang upacara tarapan. Metode yang digunakan untuk menentukan informan-informan kunci adalah "purposif sampling" dan "snowball sampling" (Sugiyono, 2006 : 300). Purposif sampling adalah teknik pengambilan sampel dengan pertimbangan tertentu, disebut juga sampling bertujuan dengan memperhatikan ciriciri tertentu pada subyek, seperti : pelaku budaya Jawa, memahami budaya Jawa, mampu memberikan informasi yang diperlukan. Teknik snowball sampling dilakukan dengan: mula-mula dicari beberapa orang informan kunci, kemudian dari informan tersebut dia bisa menunjukkan informan lain yang sesuai dengan kebutuhan penelitian. Jadi dari satu informan menunjuk informan lain dan seterusnya sehingga terpenuhi jumlah informan yang dibutuhkan yang diduga lebih tepat karena telah ditunjuk oleh orang-orang yang lebih tahu sebelumnya.

Penelitian ini dilakukan di Daerah Istimewa Yogyakarta yang merupakan pusat budaya Jawa yang berkiblat pada Kraton Yogyakarta. Setting penelitian mengambil daerah yang dekat dengan Kraton Yogyakarta, dan daerah pedesaan yang jauh dari kraton. Alasan pemilihan setting tersebut adalah adanya asumsi bahwa kehidupan di daerah yang dekat dengan kraton akan lebih kental dalam menerapkan budaya Jawa, demikian pula sebaliknya.

Data penelitian terdiri dari dua hal, yaitu: data yang berupa naskah ataupun tulisan yang berhubungan dengan upacara tarapan, diperoleh melalui metode doumentasi, yang dilakukan melalui penelusuran dokumen dari naskah-naskah budaya Jawa. Dokumen yang digunakan berupa dokumen-dokumen yang mendeskripsikan dan membahas tentang upacara tarapan yang terdapat dalam tulisan-tulisan lama tentang budaya Jawa. Data yang lain berupa informasi, pendapat, dan tanggapan mengenai upacara tarapan sebagai media pendidikan seks, didapat dari wawancara mendalam, pengamatan, dan hasil diskusi terhadap informan melalui Focus Group Discussion. Wawancara mendalam (indepth interview), dan pengamatan 
dilakukan kepada para pelaku budaya Jawa dan para anak perempuan yang mengalami haid pertama, Focus Group Discussion dilakukan dengan para informan dan pakar terkait, sehingga diperoleh suatu temuan komprehensif tentang: (1) upacara tarapan, (2). Pendidikan seksual dalam budaya Jawa. Teknik wawancara mendalam dilakukan terhadap para informan yang dipandang memahami tentang seluk beluk upacara tarapan. Wawancara ini dlakukan berulang kali guna menggali berbagai informasi mendalam sehingga diperoleh data yang komphrehensif. sesuai kebutuhan dan mampu menjelaskan tujuan penelitian. Untuk keperluan ini disiapkan seperangkat pertanyaan fokus agar pertanyaan tidak menyimpang dari tujuan penelitian

Pemeriksaan dan uji keabsahan data ini perlu dilakukan sebelum dilakukan analisis data. Teknik yang dapat digunakan adalah: perpanjangan waktu penelitian, triangulasi, dan pemeriksaan data deskriptif kepada informan yang dipandang kompeten.

Data yang sudah terlumpul dianalisis, diorganisasi, ditata dan dideskripsikan secara sistematis mengikuti pola dan kategori tertentu agar peneliti dapat lebih memahami masalah yang diteliti dan menyajikan sebagai temuan bagi orang lain Temuan penelitian ini dianalisis dan direfleksi lebih lanjut melalui upaya pemaknaan (meaningfull) atas data temuan tersebut, dengan menggunakan teori yang relevan, sehingga dapat ditarik suatu kesimpulan.

\section{HASIL DAN PEMBAHASAN Konsep Upacara Tarapan}

Pembahasan dipusatkan pada : (1) maksud dan tujuan, (2) pelaksanaan upacara tarapan,(3) perlengkapan dan persiapan upacara,(4) pantangan-pantangan. Adapun hasil penelitian yang didapatkan adalah sebagai berikut :

Hasil kajian dari Proyek Inventarisasi dan Dokumentasi Kebudayaan Daerah, Daerah IstimewaYogyakarta (1981/1982 :47) menggolongkan upacara daur hidup dalam 4 kelompok sosial, yaitu : a. Golongan Bangsawan (kelompok masyarakat berdasarkan stratifikasi sosial)

b. Golongan rakyat biasa (kelompok masyarakat berdasarkan stratifikasi sosial)

c. Golongan Petani di Pedesaan Tepi Pantai (kelompok masyarakat berdasarkan mata pencaharian dan lingkungan geografis)

d. Golongan Masyarakat Beragama Budha (kelompok masyarakat berdasarkan agama/sistem religi

Keempat kelompok sosial tersebut memiliki karakteristik masing-masing yang berpengaruh kepada pelaksanaan upacata tradisional, termasuk. upacara tarapan. Namun demikian mengingat sumber dari semua upacara tradisioanal itu dari golongan bangsawan yang tinggal di Keraton, maka pada 3 golongan lain pada prinsipnya mengikuti apa yang dilakukan oleh kaum bangsawan namun cenderung lebih sederhana sesuai dengan kondisi golongannya. Oleh karenanya apa yang dilakukan pada golongan bangsawan menjadi acuan pada pada 3 golongan lainnya.

\section{Maksud tujuan upacara tarapan}

a). Pada Golongan Bangsawan

1). Memohon perlindungan kepada Tuhan Yang Maha Esa dan doa restu kepada pinisepuh supaya terhindar dari bahaya yang selalu mengancam dalam perjalanan masa remaja, sehingga selamat dan sejahtera hidupnya lebih-lebih bagi seorang remaja puteri.

2). Melindungi atau menyelamatkan ketika anak gadis memperoleh haid pertama, yang merupakan masa krisis yang penuh dengan ancaman dari makhlukhalus jahat.

3). Untuk memenuhi adat-istiadat warisan leluhur.

4). Pemberitahuan bagi seorang puteri bahwa ia telah menginjak ke alam dewasa.

5). Mengingatkan kepada orang tua bahwa puteri mereka telah tumbuh dewasa. 
b). Pada Golongan Petani di pedesaan tepi pantai, yaitu :

1). Masa peralihan merupakan masa yang penuh bahaya. Upacara dimaksudkan untuk menolak bahaya gaib yang mengancamnya.

2). Agar anak remaja selamat.

3). Supaya anak kelak dapat menjadi penerus keturunan seperti yang diidam-idamkan.

c). Pada Golongan Beragama Buddha Kelompok sosial berdasarkan agama Buddha ini perlu ditampilakn karena adanya perbedaan-perbedaan yang agak mendasar antara agama Buddha dengan agama Islam yang dipeluk oleh sebagian besar penduduk. Agama Buddha tidak mementingkan upacara dan selamatan, namun membolehkan setiap penganutnya untuk melakukan upacara dan selamatan sesuai dengan latar belakang budaya orang yang bersangkutan, termasuk upacara daur hidup.

Pada golongan ini, maksud dan tujuan upacara tarapan :

1). Untuk menghindarkan anak yang sedang dalam keadaan kritis dari gangguan gaib.

2). Sebagai pemberitahuan kepada khalayak ramai bahwa anaknya sudah memasuki masa dewasa, status sosial yang baru.

3). Bagi umat Buddha untuk memberikan doa pemberkahan dengan tingkat perkembangan "Pancaskhandha" yang ada pada setiap individu yang berkembang menuju kesempurnaan.

\section{Pelaksanaan Upacara Tarapan di da- lam Kraton :}

Sesudah Sultan memperoleh laporan bahwa salah seorang puterinya telah tarap (haid untuk pertama kalinya) baginda mengeluarkan serta dhawuh Dalem untuk memberi tahu kepada segenap para pinisepuh puteri, para sanak kerabat puteri, dan para abdi dalem keparak, Suronoto, bahwa baginda berhajad menyelenggarakan upacara tarapan untuk salah seorang puterinya. Selanjutnya sang puteri didampingi oleh ibunya, emban menuju ke Kedhaton Kulon untuk menjalani masa pengasingan atau dipingit selama seminggu. Makan minun sehari-hari diantar. Perawatan kebersihan dilakukan oleh ibu kanding dibantu emban. Selama menjalani masa pengasingan, sang puteri hanya boleh dibersihkan dengan jalan mengusapkan air, tidak boleh mandi. Minum obat-obat tradisional dan sanggulnya diikat kuat-kuat dengan lawe. Setelah masa pengasingan berakhir sang puteri dijemput oleh ibunya, pinisepuh dan para sanak kerabat puteri, diiringi oleh para abdi dalem Keparak dan emban. Ikatan lawe dilepas, hingga rambutnya terurai. Kemudian diarak menuju ke pekobongan yang ditaruh di pelataran sebelah selatan ruang Sekar Kedathon. Sesudah masuk kedalam pekobongan, sang puteri menjalani upacara siraman (mandi) yang dilakukan oleh puteri dibantu ibu kandngnya dan para sanak kerabat puteri. Busana kraton : sabukwala, ukelan : tekuk dengan cunduk jungkat, sesudah siram ngginggit empon-empon dan delima putih. Petugas yang nyirami seperti pada upacara pengantin (manten), yaitu orang-orang yang diharapkan memiliki pengarhi positif pada anak, keluar dari tempat mandi anak diselimuti dengan kain batik yang memiliki motif tertentu, yang intinya agar masa depan anak menjadi baik.

Selesai menjalani upacara siraman, sang puteri dibawa ke Kedhaton Kulon lagi. Diberi jamu mamahan dan jamu godhogan serta telur mentah. Tubuhnya dibedaki boreh, dirias dan dikenakan busana kebesaran adat Kraton lengkap dengan perhiasannya. Selanjutnya sang puteri di antar ke Gedhong Kuning untuk melakukan upacara ngabekten kepada Sultan dengan diiringkan oleh pinisepuh puteri, segenap sanak kerabat puteri, para abdi dalem Keparak.

Setelah lurah puteri melaporkan bahwa sang puteri telah menjalani upacara tarapan dengan selamat, Sultan memberi isyarat agar puterinya memberi sembah sungkem 
(ngabekti) kepada baginda yang akan mengkaruniakan restunya dengan sang puteri bersembah dan menerima kaki ayahanda. Sultan memberikan jamuan minum kepada para pinisepuh puteri, para isterinya dan segenap sanak kerabat puteri. Selanjutnya Sultan masuk ke ruang dalam Gedhong Kuning dan segenap yang hadir sang puteri kembali ke wisma ibu kandungnya. Para abdi dalem Suronoto mengepung sajian selamatan. Lurah Suronoto mengucapkan ujub disusul dengan memanjatkan doa keselamatan dan membagi-bagi sajian selamatan. Kenduri itu menandai bahwa seluruh rangkaian upacara tarapan telah berarkhir. Pada tiga kelompok sosial yang lain, upacara yang dilakukan lebih sederhana dan menyesuaikan dengan kemampuan.

\section{Perlengkapan dan persiapan upacara}

Penyelenggaraan upacara tarapan yang berupa siraman, di kraton dilaksanakan di pelataran Kedaton Kulon (Barat), yang tinggal di luar kraton dilakukan di kamar mandi , selanjutnya ngabekten dilakukan di Gedhong Kuning, sedangkan di luar kraton, ngabekten dilakukan di ruang keluarga. Sedangkan para petugas dalam penyelenggaraan upacara tarapan di kraton adalah :

a. Para pinisepuh puteri dan ibu kandung

b. Para abdi dalem Keparak

c. Abdi dalem emban, amping

d. Para sanak kerabat puteri.

Di luar kraton :

a. Para pinisepuh puteri dan ibu kandung

b. Abdi dalem kesayangan (bapa) dan para abdi dalem lain

c. Para sanak kerabat puteri

d. Kaum.

Pihak-pihak yang terlibat dalam upacara

di Kraton adalah :

a. Puteriyangakan menjalani upacara tarapan dan ibu kandungnya.

b. Sultan.

c. Para pinisepuh puteri.

d. Para sanak kerabat puteri.

e. Para abdi dalem Keparak.

f. Abdi dalem emban, amping.

g. Abdi dalem Suronoto. lah

Pihak yang terlibat di luar Kraton ada-

a. Puteri yang akan menjalani upacara tarapan

b. Ibu dan ayah kandung.

c. Para pinisepuh puteri.

d. Abdi kesayangan (bapa) dan para abdi dalem lain.

e. Para sanak kerabat puteri.

f. Kaum.

Persiapan dan perlengkapan upacara di Kraton adalah sebagai berikut :

Adat Kraton menetapkan bahwa tarapan merupakan suatu upacara daur hidup yang penting bagi setiap puteri Sultan. Sultan yang menentukan persiapan upacara tarapan dan mengeluarkan serat dhawuh Dalem (Suart pemberitahuan Sultan) kepada para pinisepuh puteri, para sanak kerabat puteri dan para abdi dalem Keparak serta abdi dalem lainnya untuk melakukan persiapan upacara dan menyediakan semua perlengkapan upacara.

Perlengkapan upacara tarapan yang berupa benda-benda dan lain-lain adalah :

a. Pekobongan, perlengkapan ini sama dengan perlengkapan yang digunakan untuk siraman dalam upacara tetesan yang berisi :

1). Semacam balai-balai beralaskan permadani atau tikar pasir. Aneka macam motif kain yang berbentuk persegi empat atau bujur sangkar, (Sindur, bangun tulak, lurik puluh watu, yuyu sekandang, lerek jingga)., dan kain mori putih, semuanya ditaruh di atas tikar yang disebut : klasa bangka, yaitu tikar yang terbuat dari mendhong dengan anyaman yang besar-besar.

2). Aneka macam dedaunan : daun kluwih, daun apa-apa, daun kara, daun dhadhap serep, rumput alang-alang atau ilalang. Berbagai dedaunan itu ditindhih dengan tikar (klasa bangka).

3). Pisau kecil, kapuk kapas, cowek, kunyit.

Selanjutnya di dalam pekobongan untuk siraman, terdapat : 
a). Bangku kecil diberi tikar

b). Air yang diberi bunga setaman dan direndami 2 kelapa utuh.

c). Periuk kecil dari tanah (klenthing) berisi air yang telah diberi mantra.

d). Bulatan tepung beras, berjumlah tujuh dalam tujuh warna, untuk menggosok badan.

e). Keramasan, berupa air merang campur air asam untuk keramas rambut, mangir, bahan penggosok badan.

f). Klenthing yang berisi air yang sudah diberi mantra.

g). Air kembang setaman atau sritaman.

h). Kain-kain berbentuk segi empat atau bujur sangkar dengan motif-motif : lerek jingga, bangun tulak, lurik puluh watu, yuyu sekandhang, sindur, dan kain mori putih, yang semuanya diletakkan di atas tikar (klasa bangka).

i). Dedaunan aneka macam : daun apaapa, kluwih, kara, dhadhap srep, rumput alang-alang atau ilalang

\section{b. Perlengkapan busana .}

Adapun perlengkapan busana yang dikenakan terdiri atas : nyamping cindhe, lonthong kamus bludiran, udhet cindhe, slepe, gelangkana, sangsangan sungsun, mengenakan subang serta cincin. Sanggulnya berbentuk tekuk dengan hiasan pethat gunungan. Di bagian tengah sanggul dikenakan bros, lancur, serta peniti renteng, sebagai jebehan di kiri kanan. Kain cindhe untuk upacara tarapan ini dikenakan dengan model pinjung (Mari S. Condronegoro, 1995 : 24).

c. Ampilan, yaitu benda-benda upacara yang berupa antara lain :

1). Satu set tempat minum kemasan (untuk puteri Sultan) yang ditaruh diatas nampan.

2). Bersekan, tempat alat-alat kecantikan. Jumlah bersekan ada 2 pasang: yang sepasang memuat 2 tempat minyak kelapa (cemceman) dan sebuah tempat bedak; yang sepasang lagi memuat 2 botol air mawar, 2 ge- las haarnet, jarum, penjepit rambut, dan 1 botol minyak wangi.

3). Cermin, sumbul ( tempat gelas untuk minum jamu).

4). Baki 2 buah : yang satu tempat busana mandi, seperti handuk, kain basahan, dan lain-lain; yang satunya berisi busana kebesaran dan perhiasan.

5). Bantal guling perhiasan dari kain cinde.

6). Tempat jamu beras kencur.

7). Tempat tidur tiruan (pasarean pajangan). Pasarean pajangan ini untuk para puteri Sultan.

8). Jamu mamahan, jamu untuk dikunyah, terdiri atas: beras kencur, kunyit, asam, katu legi, ketumbar, trawas.

9). Megar mayang dan tetuwuhan, terdiri atas : tebu, kelapa utuh, padi dan pisang.

10). Anglo, arang, kemenyan.

d. Perangkat sesajian. Perlengkapan sesajian terdiri atas dua perangkat yang sama: yang satu perangkat ditaruh di depan pekobongan untuk siraman, atau di dekat kamar mandi, sedangkan yang satu perangkat di taruh di depan pekobongan untuk tarapan.

Kedua perangkat sesajian itu, masing-masing terdiri atas :

1). Tumpeng robyong, gundhul.

2). Jajan pasar.

3). Gula Jawa, kelapa utuh, telur mentah, beras.

4). Ketan moncowarno.

5). Apem, kolak, ketan.

6). Srabi, klepon, clorot, kupis, lepet, jongkong, inthil.

7). Sekul wuduk, tumpeng kencono.

8). Polowidjo : polo kependhem, polo gumantung, polo kasimpar, juga tebu dan padi.

9). Impling, candu waron, wedang bubuk. 10). Seekor ayam hidup.

11).Sesajian bucalan (untuk dibuang). 


\section{Pantangan-pantangan}

Pantangan yang harus dipatuhi antara lain adalah :

a. Seorang puteri yang sedang dipingit (dalam pengasingan selama seminggu, dilarang mandi dan keluar kamar atau ruangan, kecuali untuk keperluan ke toilet.

b. Rambut dilarang lepas terurai.

c. Kemana-mana harus memakai sandal supaya tidak menginjak telek (kotoran) agar tidak berbau.

d. Kalau berjalan tidak boleh lewat di bawah memean (jemuran)

e. Dilarang tidur tanpa alas bantal.

f. Tidak boleh makan dengan lauk pauk tertentu, misalnya : ikan asin, tempe goreng dan lain-lain yang cenderung menimbulkan bau amis. Pantangan makanan yang terkait bau darah, jadi makanan yang tidak amis-amis

g. Sesudah menjalani upacara tarapan, tidak dibenarkan tidur sekamar dengan ibunya.

\section{Nilai pendidikan yang terdapat dalam upacara tarapan}

\section{Bagi Anak :}

a. Selesai hari ketujuh dari masa haid dilanjutkan dengan siraman, dengan pakaian adat lengkap, diberi obatobatan tradisional jamu mamahan dan jamu godhogan, menelan telur mentah), alas duduk dari dedaunan dan empon-empon, untuk menjaga kesehatan, kebugaran, serta kecantikan. Pemberian jamu-jamu tradisional tersebut, juga merupakan pendidikan perilaku hidup sehat bagi remaja. Selanjutkan diadakan kenduri dan pembacaan doa untuk memohon keselamatan

b. Anak memahami bahwa kini ia sudah menjadi remaja, harus bisa mengurus dirinya sendiri : menjaga kebersihan sehubungan dengan hadirnya haid, pada masa lalu menghadapi datangnya haid agak menyulitkan bagi seorang gadis, terutama men- jaga agar darah yang keluar tidak pernah tampak oleh orang lain yang akan membuat malu. Namun saat ini hal itu dipermudah dengan hadirnya pembalut wanita yang sangat membantu gadis menjaga kebersihannya.

c. Anak kini perlu menyadari bahwa dirinya sudah matang secara seksual, artinya bila terjadi hubungan seksual tidak mustahil terjadi kehamilan. Oleh karenanya anak perlu hati-hati dalam pergaulan dengan lawan jenis demi menjaga kesuciannya.

d. Kesadaran akan dirinya, bahwa dia bukan anak-anak lagi akan membawanya pada tutur kata dan tindaktanduk yang lebih dewasa tidak kekanak-kanakan lagi.

\section{Bagi Orang Tua:}

a. Menyadarkan para orang tua bahwa kini, putrinya sudah menginjak remaja, perlu mendampingi bagaimana mengelola masa haid. Haid adalah gejala wajar bagi anak yang menandai anak memasuki masa remaja. Tanpa adanya upacara seperti yang sekarang terjadi, banyak orang tua yang tidak memahami bahwa puterinya sedang menghadapi datangnya haid, yang sering menimbulkan kegoncangan atau stress bagi anak yang sangat membutuhkan pendampingan.

b. Meningkatkan kepedulian orang tuanya akan keberadaan puterinya yang kini sudah menginjak masa remaja, yang menuntut pengawasan khusunya yang terkait dengan hubungannya dengan pergaulan dengan lawan jenis.

c. Jika masa lalu orang belum terlalu sibuk dengan pekerjaan, kini orang tua sangat sibuk, sehingga tidak mustahil masa peralihan yang sering menimbulkan stress pada anak kurang atau tidak mendapatkan perhatian dari orang tua. 


\section{SIMPULAN}

Upacara tarapan merupakan salah satu dari daur kehidupan manusia, yaitu daur kehidupan anak-anak menuju masa remaja (dewasa).

1. Di Daerah Istimewa Yogyakarta dikenal adanya 4 stratifikasi sosial dalam melaksanakan upacara tarapan, yaitu : a. Golongan Bangsawan; b. Golongan Rakyat Biasa; c Golongan Petani di Pedesaan Tepi Pantai; dan d. Golongan Beragama Budha, oleh karenanya dalam melaksanakan upacara tarapan disesuaikan dengan latar belakang kondisi masingmasing.Upacara tarapan yang dilakukan oleh golongan Bangsawan yang tinggal di Keraton merupakan sumber atau acuan bagi tiga strata sosial yang lain. Oleh karenanya upacara yang dilakukan oleh ke 3 golongan lainnya pada dasarnya mengacu apa yang dilakukan di Kraton, dengan penyesuaian, penyederhanaan sesuai dengan latar belakang masingmasing golongan.

2. Butir-butir pelaksanaan uapacara tarapan meliputi : a. Maksud dan Tujuan; b. Jalannya Upacara Tarapan; c. Persiapan dan Perlengkapan Upacara Tarapan; dan d. Pantangan-pantanagn.

3. Butir-butir Kearifan Lokal Yang Bermuatan Nilai Pendidikan pada Upacara Tarapan diantaranya adalah :

\section{a. Bagi Anak :}

(1) Sesudah hari ketujuh masa haid, dilanjutkan dengan siraman, dikenakan pakaian adat lengkap, kemudian diberi berbagai obatobatan tradisional yang berupa jamu mamahan dan jamu godhogan, menelan telur mentah, diberi alas duduk yang berasal dari dedaunan dan empon-empon, yang semuanya dimaksudkan untuk menjaga kesehatan, kebugaran, serta kecantikan dari anak tarap. Pemberian jamu-jamu tradisional tersebut, juga merupakan pendidikan perilaku hidup yang sehat yang harus dilakukan oleh seorang perempuan. Selanjutkan akan dilaksanakan kenduri dan pembacaan doa untuk memohon keselamatan

(2) Anak memahami bahwa kini ia bukan kanak-kanak lagi, ia sudah menjadi remaja, yang harus bisa mengurus dirinya sendiri : menjaga kebersihan sehubungan dengan hadirnya haid, pada masa lalu menghadapi datangnya haid agak menyulitkan bagi seorang gadis, terutama menjaga agar darah yang keluar tidak pernah nampak kelar karena ketidak sempurnaan menjaganya. Namn saat ini hal itu dipermudah dengan hadirnya pempers yang sangat membantu gadis menjaga kebersihannya.

(3) Menyadarkan anak untuk menjaga kesuciannya, menjaga diri dari pergaulan lawan jenis, mengingat dirinya sudah matang secara seksal, artinya bila terjadi hubungan seksual tidak mustahil terjadi kehamilan. Oleh karenanya anak perlu hati-hati dalam pergaulan dengan lawan jenis demi menjaga kesuciannya.

(4) Kesadaran akan dirinya memasuki masa remaja akan membawanya pada tutur kata dan tindaktanduk yang lebih dewasa tidak kekanak-kanakan lagi.

\section{b. Bagi Orang Tua:}

(1) Menyadarkan para orang tua bahwa kini, putrinya sudah menginjak remaja. Orang tua perlu membekali puterinya tentang bagaimana mengelola masa haid. Haid adalah gejala wajar bagi anak yang menandai anak memasuki masa remaja. Karena tanpa adanya upacara seperti yang sekarang terjadi, banyak orang tua yang tidak memahami bahwa puterinya sedang meng- 
hadapi datangnya haid, yang sering menimbulkan stress bagi anak. Orang tua perlu menenangkan anak bahwa haid adalah gejala wajar bagi seorang gadis, bahkan tidak wajar jika tidak memperoleh haid.

(2) Meningkatkan kepedulian orang tuanya akan keberadaan puterinya yang kini sudah menginjak masa remaja, yang menuntut pengawasan khusunya yang terkait dengan hubungannya dengan pergaulan dengan lawan jenis.

(3) Jika masa lalu orang belum terlalu sibuk dengan pekerjaan, kini orang tua sangat sibuk, sehingga tidak mustahil masa peralihan yang sering menimbulkan stress pada anak kurang atau tidak mendapatkan perhatian sama sekali bagi orang tua.

Upacara tarapan yang telah kita miliki dan sampai sekarang masih berlangsung di Kraton Yogyakarta, meskipun saat ini sudah banyak ditinggalkan oleh rakyat biasa perlu dijaga kelestariannya sebagai kekayaan adat tradisional. perlu dikenali oleh masyarakat khususnya warga Yogyakarta, dengan cara: a. Mengadakan peragaan atau simulasi tentang pelaksanaan upacara tarapan agar dikenal oleh masyarakat luas. Simulasi ini dapat dilakukan oleh dinas yang terkait seperti : Dinas Pariwisata, Dinas Kebudayaan atau lembaga lain seperti Perguruan Tinggi yang relevan dengan upacara ini.

b. Memperbanyak tulisan oleh pemerhati yang dimuat di koran lokal /nasional, majalah, lebih-lebih yang berbahasa Jawa agar dibaca banyak orang.

c. Menyelenggarakan seminar atau sarasehan untuk menggali dan mendengungkan eksistensi upacara tarapan sebagai kekayaan budaya yang pernah kita miliki sebagai upacara tradisional.

\section{DAFTAR PUSTAKA}

Ani Rostiyati, 1995, Fungsi Upacara Tradisional Bagi Masyarakat Pendukungnya Masa Kini, Yogyakarta, Jarahnitra-Depdikbud

Departemen Pendidikan dan Kebudayaan, Proyek Inventarisasi dan Dokumentasi Kebudayaan Daerah, 1981/1982, Upacara Tradisional Daerah Istimewa Yogyakarta, Departemen Pendidikan Dan Kebudayaan.

DNST, 1981. Pola Penelitian Kerangka Laporan dan Petunjuk Pelaksanaan, Proyek IDKD Departemen P \& K Jakarta

Fanani, Achmad, 2004, Pendidikan Seks Untuk Keluarga Muslim, Yogyakarta, Penerbit: ORCHID

Koentjaraningrat, 1984, Kebudayaan Jawa, Jakarta : PN. Balai Pustaka.

Maharkesti, 1996/1997. Tarapan di Lingkungan Kraton Yogyakarta, dalam Laporan Penelitian JARAHNITRA. Departemen Pendidikan Dan Kebudayaan, Direktorat Jenderal Kebudayaan, Direktorat Sejarah Dan Nilai Tradisional, Balai Kajian Sejarah Dan Nilai Tradisional Yogyakarta.

Mappiare, Andhi, 2002. Psikologi Remaja, Surabaya, Usaha Nasional

Mari S. Condronegoro. 1995. Busana Adat Kraton Yogyakarta: Makna dan Fungsi dalam berbagai Upacara. Yogyakarta :Yayasan Pustaka Nusatama. .

Melly S. Rifai, 1987, Psikologi Perkembangan Remaja, Jakarta: PT. Bina Aksara

Miles, M.B. \& Huberman, A.M. 1992. Analisis Data Kualitatif. Jakarta : penerbit Universitas Indonesia.

Nina Surtiretna, 2006, Remaja dan Problema Seks, Tinjauan Islam dan Medis, Bandung, Remaja Rosdakarya

Sarlito Wirawan S. 2006, Psikologi Remaja, Jakatarta, PT. Grafindo Persada

Sugiyono. 2006. Metode Penelitian Pendidikan. Bandung : Alfabeta.

Supajar, Damarjati, 1985, Etika dan Tata Krama Jawa Dahulu dan Masa Kini, Yogyakarta, Javanologi Depdikbud Yogyakarta. 